\title{
The Overnight Return Temporal Market Anomaly
}

\author{
Vasiliki A. Basdekidou ${ }^{1}$ \\ ${ }^{1}$ SRFA Aristotle University of Thessaloniki, Greece \\ Correspondence: Vasiliki A. Basdekidou, Special Research Fund Account (ELKE), Aristotle University of \\ Thessaloniki, Greece. Tel: 302-310-996-000. E-mail: Vasiliki.Basdekidou@ gmail.com
}

Received: Septemper 15, 2016

Accepted: January 29, 2017

Online Published: January 29, 2017

doi:10.5539/ijef.v9n3p1

URL: http://dx.doi.org/10.5539/ijef.v9n3p1

\begin{abstract}
The main goal of this paper is to introduce an innovative market anomaly relating to "time" during the overnight post-market session and therefore characterized as a temporal market anomaly. Anomalies in the markets appear from time to time and test the efficient market hypothesis. Many investors and traders believe that the markets follow the efficient market hypothesis. According to this theory the current price of a security (trading instrument) reflects all public and private information about that security (instrument). Changes in price are due to insider information, current news, or sudden events, which are impossible to predict. Hence, security's price action follows the path of a random walk, the hypothesis and argument of which states that current price is not dependent on past price and is normally or abnormally distributed over time. In financial and economical literature, many studies have presented approaches about what the academics call "market anomalies" and according to literature the anomalies are classified in three categories: Fundamental, Technical, and Calendar-based anomalies. In this article another class of market anomalies is introduced, that simply could be referred to as "temporal" because of the timing functionality involved. Finally, I will discuss one of these "temporal" anomalies, called the overnight return temporal market anomaly. The presented research shows that momentum profit accumulates entirely overnight, while profit on all other strategies occurs entirely intraday. These findings strongly reject classical theories of intraday versus overnight returns.
\end{abstract}

Keywords: market anomalies, liquidity, market timing, temporal (timing) trading functionalities (TTF), temporal market anomalies, intraday vs. overnight returns

\section{Introduction}

The main goal of this paper is to introduce a new market anomaly, challenging the efficient market hypotheses and relating to "time" during the overnight post-market session (Ang et al., 2006; Bali \& Cakici, 2008; Basdekidou, 2015; Basdekidou, 2016b). This innovative anomaly characterized and documented as a temporal market anomaly (Basdekidou, 2017; Basdekidou \& Styliadou, 2017).

\subsection{Problem Introduction}

In corporate finance literature, both the risk-based and the expected returns were examined in detail (Vayanos \& Woolley, 2013; Campbell et al., 2014). In this domain, understanding cross-sectional variants in returns is critical for market and stock evaluation and trading purposes (Lou et al., 2016).

Trading is regarded as a temporal historical living system (Styliadis, 2007; Styliadis \& Vassilakopoulos, 2005) with a number of time-based anomalies challenging the efficient market hypothesis and initiating relative trading functions. Anomalies in the markets appear from time to time and test the efficient market hypothesis. Many investors and traders believe that the markets follow the efficient market hypothesis. According to this theory the current price of a security (trading instrument) reflects all public and private information about that security (instrument). Changes in price are due to insider information, current news, or sudden events, which are impossible to predict. Hence, security's price action follows the path of a random walk, the hypothesis and argument of which states that current price is not dependent on past price and is normally (or abnormally) distributed over time (Livermore 1940/2001).

In financial and economical literature, many studies have presented approaches about what the academics call "market anomalies" and according to literature the anomalies are classified in three categories: Fundamental, Technical, and Calendar-based anomalies (Demiralp et al., 2011; Basdekidou, 2015). Current paper reasoning that there is also another class of anomalies that simply could be referred to as "temporal" because of the timing 
functionality involved. In this article I will discuss one of these "temporal" anomalies, called the overnight return temporal market anomaly. Historically, market anomalies have a great temporal (timing) trading functionality (Hovakimian \& Hu, 2016; Basdekidou, 2016b), resulting in excellent profit \& wealth growth opportunities.

The observed mispricing in price action, as a typical technical market anomaly, camouflaged such as trading timing and could be regarded as the result of the lack of any available temporal trading functionality (TTF) for the investors, traders, institutions and speculators, and for the embedded time-based behavioral biases dominant in securities (equities), Forex and option markets ((Ogden \& Wu, 2013; Basdekidou \& Styliadou, 2017). The main reason that the institutions and the long-term investors usually buy overbought shares, is explained in Edelen, Ince, and Kadlec (2015), who in their paper reasoning that long-term investors, traders and speculators prefer to build positions on shares classified as overbought (i.e. a momentum trading psychology functionality) based on a number of classical equities-trading strategies (i.e. a "trend-follow" trading, but without any TTF functionality in this case) (Basdekidou, 2016a; Choie, 2016). Financial economics approaches emphasize that disengagement of holding and domination has as a result the clash of interest between outside collaborators, stakeholders, CEOs, and governors. In this domain, the literature reasoning is that big corporate shareowners (not interested in short-term trading, nor using TTF functionalities in their trading plans) can ease and lighten such things as "conflict arguments" by observing and controlling CEOs through the SEC reports (Hartzell \& Starks, 2003).

Also, in economics and finance, timing in trading approaches try to clarify such attitude, assuming that any trading decision (i.e. open/close positions; lot trade size, etc.) is formed for the regard of old non-speculative shareowners (investors), who adequately take profit from trading shares just as a consequence of right-timing daily trading initiatives based on short-term (intraday) time trading functionalities (intraday TTF) and not as a result of a well-designed, based on long-term TTF, trading strategy (Baker \& Wurgler, 2002). The current paper agrees that the data are consistent and produce profit with such expectations, as far as the timing of the trading initiatives and executive orders (open/close position) is regarded as TTF functionality (Skyba, 2012).

\subsection{The Overnight Return Anomaly Rule}

Lou et al. (2016) deliver remarkable new evidences about intraday and overnight returns. According to their research, nearly $100 \%$ of the abnormal (i.e. market anomalies) returns on momentum strategies occur overnight. On the other hand, according to Lou et al., the average intraday component of momentum profit is statistically insignificant. Their findings are subject to a number of controls and risk-adjustments. So, the overnight return is bigger among large-cap stocks, 3x ETFs/ETNs (Note 1) instruments, and stocks with relatively large prices. The presented result is inconsistent with the classical theories and explanations about intraday and overnight trading return. Hence, this inconsistency could be characterized as a new market anomaly not belonging to well-known fundamental, technical or calendar-based anomalies. The rule for this new anomaly is defined as follows:

The Overnight Return Anomaly (ORA) rule:

Buy at the Close of the current daily session.

Hold position overnight.

Sell at the Open of the next day's session.

\subsection{Problem Importance Exploration}

In securities trading "timing" (stocks, options, Forex, ETF, ETN, instruments, etc.), Cesari, Espenlaub, Khurshed, and Simkovic (2012) argue and disagree on the effects of share-holding and stock liquidation on the timing transactions for open and close positions ("buy" in case of a short position; and "sell" in case of a long position), but in their paper no more details for short-term or daily and intraday TTF functionalities were given; and Demiralp, D'Mello, Schlingemann, and Subramaniam (2011), in their paper, state that old-issue share returns and passive trading, are both strongly connected with the coexisting of old-issue changes in corporate holding for a time period as long as up to 3 years after the TTF time. Obviously, this period is regarded as too big, even for the "buy-and-hold" investors, for nowadays swing and volatile securities markets traded on a daily and intraday bases; e.g. leveraged 3x ETFs; Gold, Silver, WTI Oil, and Natural Gas ETNs; etc.

Daytime (intraday) versus overnight returns can be studied by analyzing the differences in returns between the day's session (defined here as regular NYSE trading hours) and the overnight after-hours post- and pre-session period. In testing the returns for the day and overnight periods, I used the SPDR S\&P 500 ETF (SPY) from January 1, 2010 to June 30, 2016. I define the day's return (TTF functionality) as the price difference between the day's open and the day's close. The overnight return (TTF functionality) is the difference between the day's close and the following morning's open (Basdekidou \& Styliadou, 2017). 


\subsection{Motivation and Previous Literature}

The current article, as far as the trading timing is concern, is relative to some other articles that investigate corporate share-holding under the prism of the trading timing. In this frame, some articles (Choie, 2016; Markoulis \& Neofytou, 2016) targeted on the information asset and stock-taking intelligence of corporate investors, while others (Hao, 2014; Baker, Stein, \& Wurgler, 2003; Gibson, Safieddine, \& Sonti, 2004) targeted on the trading strategies, tactics and plans, but in both cases no TTF information was given.

Chemmanur, He, and Hu (2009) find that long-term passive-trading investors (as opposed to non-commercial short-term investors, traders, overnight and intraday speculators) are likely to experience bigger share positions in SEOs and IPOs hoping on better returns and their transactions somewhat greatly exceed a passive "buy-and-hold" trading strategy with no (trading) psychological timing (Nguyen \& Tran, 2016; Basdekidou, 2016a; Hovakimian \& Hu, 2016). In this article the (trading) psychological timing functionality is apparent and obvious but the daytime and overnight alternatives are not discussed (Livermore 1940/2001).

In accordance to the above situation, Edelen, Ince, and Kadlec (2015), examined corporate trading and securities (instruments) return divergences, and discovered that corporate firms prefer to purchase shares categorized as overbought and this is regarded as a non-positive association (i.e. relationship functionality) in trading timing. Also, in this article the (trading) psychological timing functionality is apparent and obvious but the daytime and overnight alternatives are not discussed.

In opposition to these articles that spotlight mainly on whether long-term investors and old-shareowners are better-informed (i.e. insiders functionality), rather on the (trading) psychological timing TTF functionality; the current research article targets on the dominant relationship between trading and timing and the underlined trading functionalities (Basdekidou, 2016b; Livermore 1940/2001).

Alti and Sulaeman (2012) also expressed a disagreement to these articles, by pointing out how new shares issuing initiatives (IPOs) are influenced by corporate and non-commercial trading. Actually, they support the position that strong securities trading returns trigger equity derivation only if it is connected with a great pre-issue corporate investor demand (supply vs. demand approach), as it is regarded to be consistent with the new corporate holdings (i.e. swing momentary traders). Alti and Sulaeman also clarify their results as logical and dependable with trading initiatives using the corporate investor supply vs. demand functionality as a gauge of the market's interest in the company's equity initiative. Also, in this article the (trading) psychological timing functionality is apparent and obvious but the daytime and overnight alternatives are not discussed.

In this domain, the main target of the current article is divergent. Actually, I investigate whether the overnight shareowners, as short-term investors, gain profit from the proposed overnight return temporal market anomaly. It is notable that, the results obtained does depend on the trading instrument (e.g. 3x leveraged ETF/ETN; index-based ETF; etc.) and therefore always an adaptive personalized functionality is involved ("volatility" in case of the trading instrument and "user profile" for the case of the investors, traders, and momentary speculators) in designing overnight return based trading strategies.

\subsection{Paper's Structure}

The rest of the article is organized as follows: Section 2 ("Trading Data: Daytime \& Overnight Returns") describes the trading data as the daytime and overnight return variables; Section 3 ("Analysis: The Overnight Return Temporal Market Anomaly") documents the introduced innovative term by examining the relation between daytime and overnight timing trading, as well as the impact of the adaptive personalized instrument selection on this "timing"; Finally, Section 4 ("Conclusions \& Discussion") summarizes the conclusions and discusses paper's innovations and contributions.

\section{Trading Data: Daytime \& Overnight Returns}

The main difference between intraday (daytime: 09:30 am - 04:00 pm EST) and overnight periods is that much of the overnight return has earnings announcements functionality (at least for the USA stock markets) and therefore may reflect information surprises. Nearly a $25 \%$ of these overnight earnings announcements published in the first 30 minutes after market close; while the $60 \%$ published in the morning before market opening.

According to my review of the 2010-2016 data, companies tend to submit important regulatory filings just after market closing. Barclay and Hendershott (2003) find that though price action is more active and efficient during the intraday period, after-hours trading contain more information and support greater trading functionality than the daytime trading. Also, according to my research with the pre-open auctions on the NYSE and NYSE Arca, the same conclusions were documented. 
For the current paper, the profit/losses trading data (2010-2016) for the UGAZ 3x leveraged Exchange-Traded Note (ETN) (VelocityShares, 2017) came from many resources. The Barron's information databases and sources, a Wall Street Journal affiliate (Barron's, 2016); the StockCharts.com initiative; the Securities \& Exchange Commission/SEC notices, releases \& announcements; the Commitments of Traders (CoT)/CFTC speculative net positions reports; the Yahoo! Finance insiders data feed; the SEC EDGAR database; and the Thomson Financial corporate holdings database (Nguyen \& Tran, 2016; Basdekidou, 2016a; Baker \& Wurgler, 2002; Barclay \& Hendershott, 2003; Livermore 1940/2001).

The proposed volatility-strategy and volatility-tactical can be used in concert with stocks, leveraged instruments, ETFs, ETNs, swaps, futures, and/or options to implement risk management strategies and it is dedicated to providing individual traders and institutional investors with sophisticated solutions for portfolio and trading risk management: (i) reward to risk ratios; and (ii) stop-loss and stop-profit sell orders. The proposal's success results from delivering innovative, efficient, and intelligent functionality for a wide range of intraday traders and institutional investors.

In this paper, the above numbers were used to estimate, with an acceptable standard deviation (st. dev., $\sigma$ ), total corporate securities profit / loss and position changes (if applicable) and for a period from January $1^{\text {st }}, 2010$ to June $30^{\text {th }} 2016$ (Yan \& Zhang, 2009). So, for each of the above thirteen (13) semesters, the traders involved parameterized as overnight and daytime returns for the UGAZ 3x leveraged ETN (VelocityShares (Note 2)) and categorized as profit or loses in following Figures 1 and 2.

The result is an unbalanced panel, covering the sample time period from January $1^{\text {st }}$ (2010) to June $30^{\text {th }}(2016)$, with more than 2,000 observations used in the back-testing procedure. The presentation equity curve (returns), in Figures 1 and 2, incorporates the standard deviation for a quality interpretation of both trading strategies: Overnight and Intraday (Vayanos \& Woolley, 2013; Campbell et al., 2014; Lou et al., 2016; Hovakimian \& Hu, 2016; Livermore 1940/2001).

Overnight Returns: Exchange-Traded Note (3x ETN) Curve Detailed - UGAZ Daily (01/01/2010 16:00 - 30/06/2016 16:00)

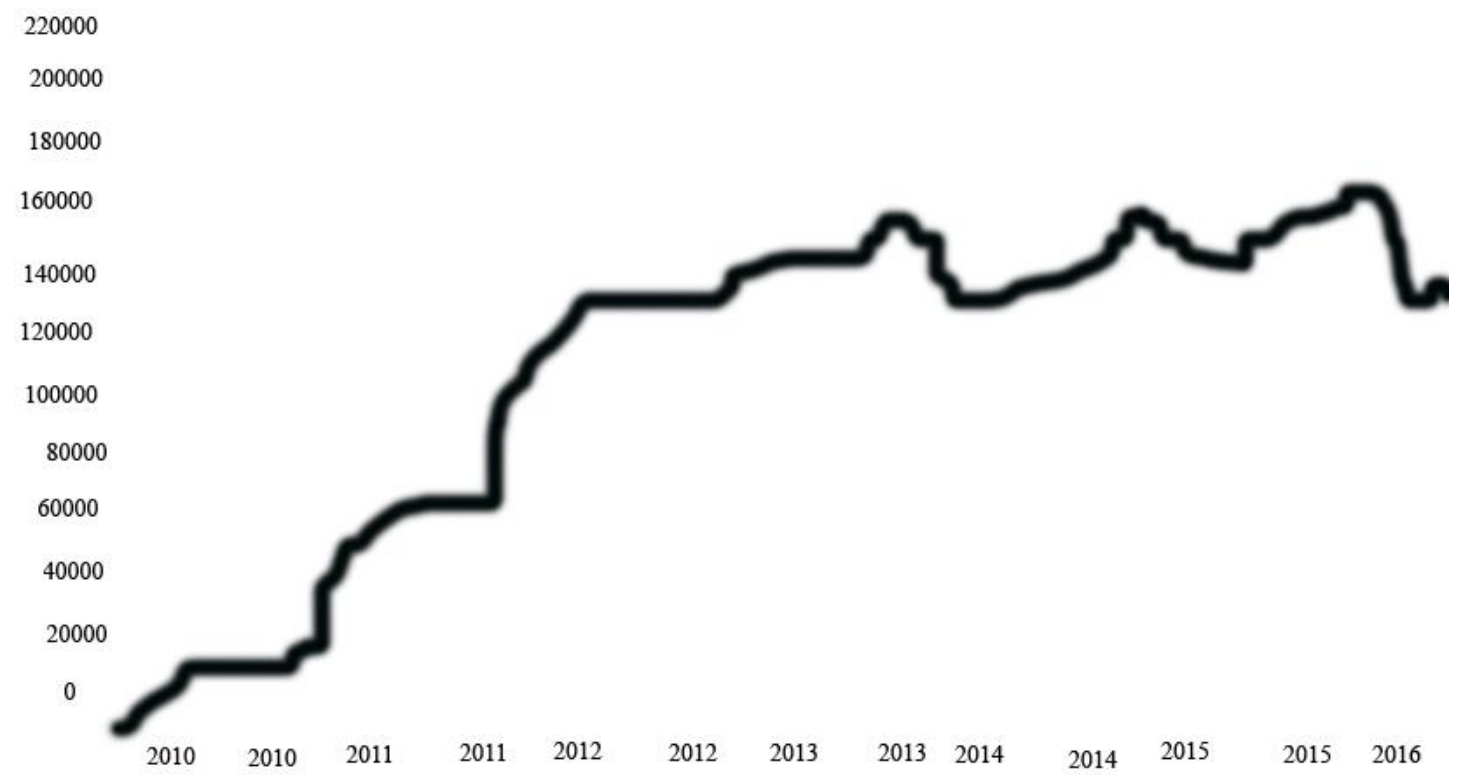

Figure 1. UGAZ 3x ETN, from 1/1/2010 to 30/06/2016

Note. The equity curve of Overnight Returns (today's open - yesterday's close) of $\$ 100,000$ invested per trade is displayed. Transactions don't include commission or slippage costs. 


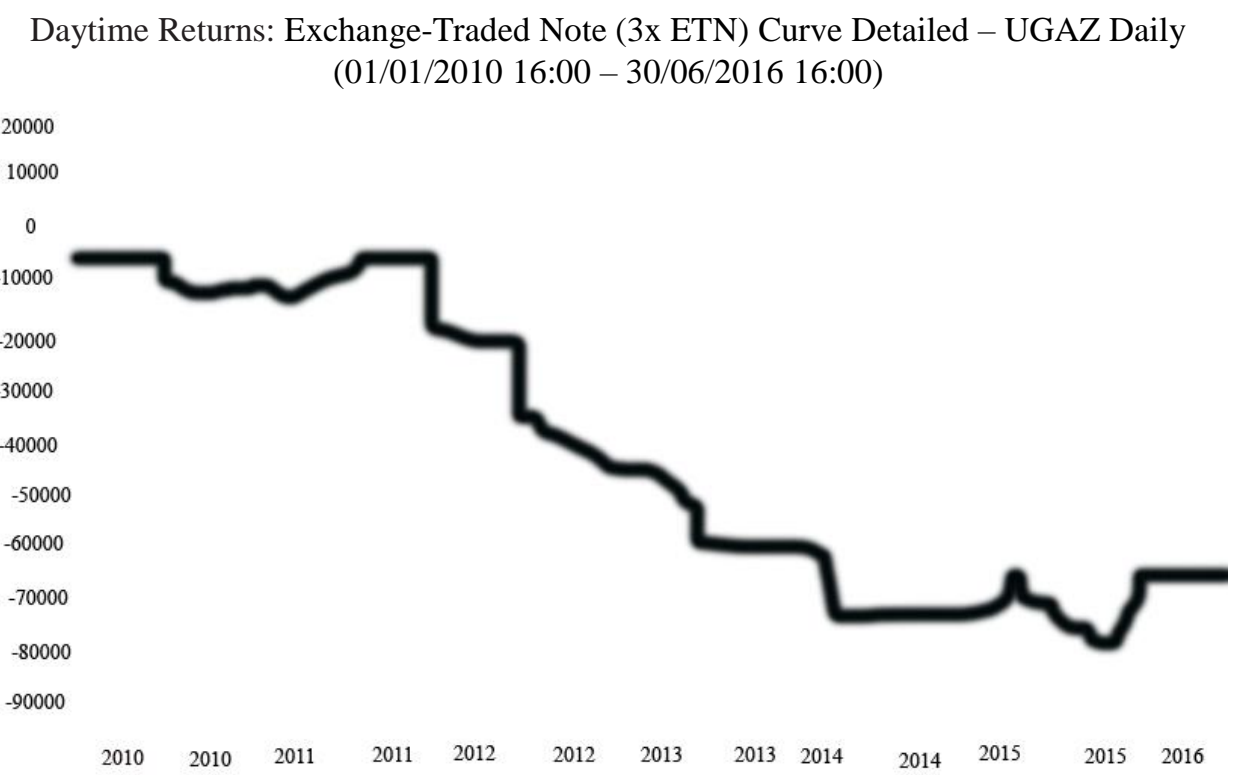

Figure 2. UGAZ 3x ETN, from 1/1/2010 to 30/06/2016

Note. The equity curve of Daytime Returns (today's close - today's open) of $\$ 100,000$ invested/trade is displayed. Transactions don't include commission or slippage costs.

It is a common misinterpretation between the market participants that the majority of returns from short-term trading are extracted from the daytime (intraday), rather than from the overnight period. This would make sense, as more people are active during the normal daytime hours as opposed to the overnight period (i.e. a strong emotional relation to relative price actions in case of trading). But, as Figures 1 and 2 indicate, the opposite is true of day vs. overnight returns. Following, Figures 3 (overnight returns) and 4 (daytime returns) display the equity curve detailed for the SPY 1x ETF daily and for the period 02/02/1993 - 15/06/2011 (Skyba, 2012).

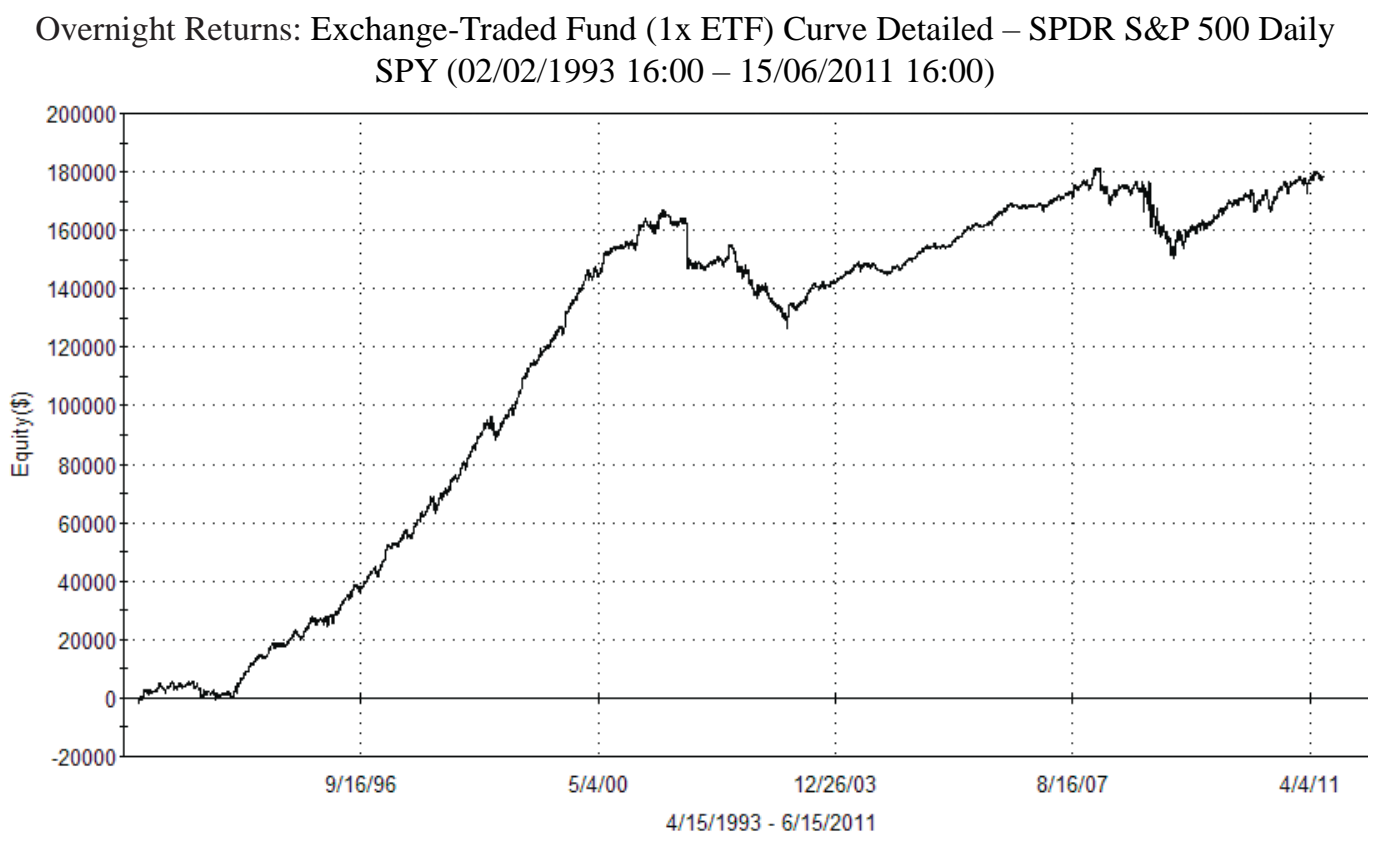

Figure 3. SPDR S\&P 500 1x ETF, from 2/2/1993 to 15/6/2011

Note. The equity curve of Overnight Returns (today's open - yesterday's close) of $\$ 100,000$ invested per trade is displayed. Transactions don't include commission or slippage costs. 
Daytime Returns: Exchange-Traded Fund (1x ETF) Curve Detailed - SPDR S\&P 500 Daily SPY (02/02/1993 16:00 - 15/06/2011 16:00)

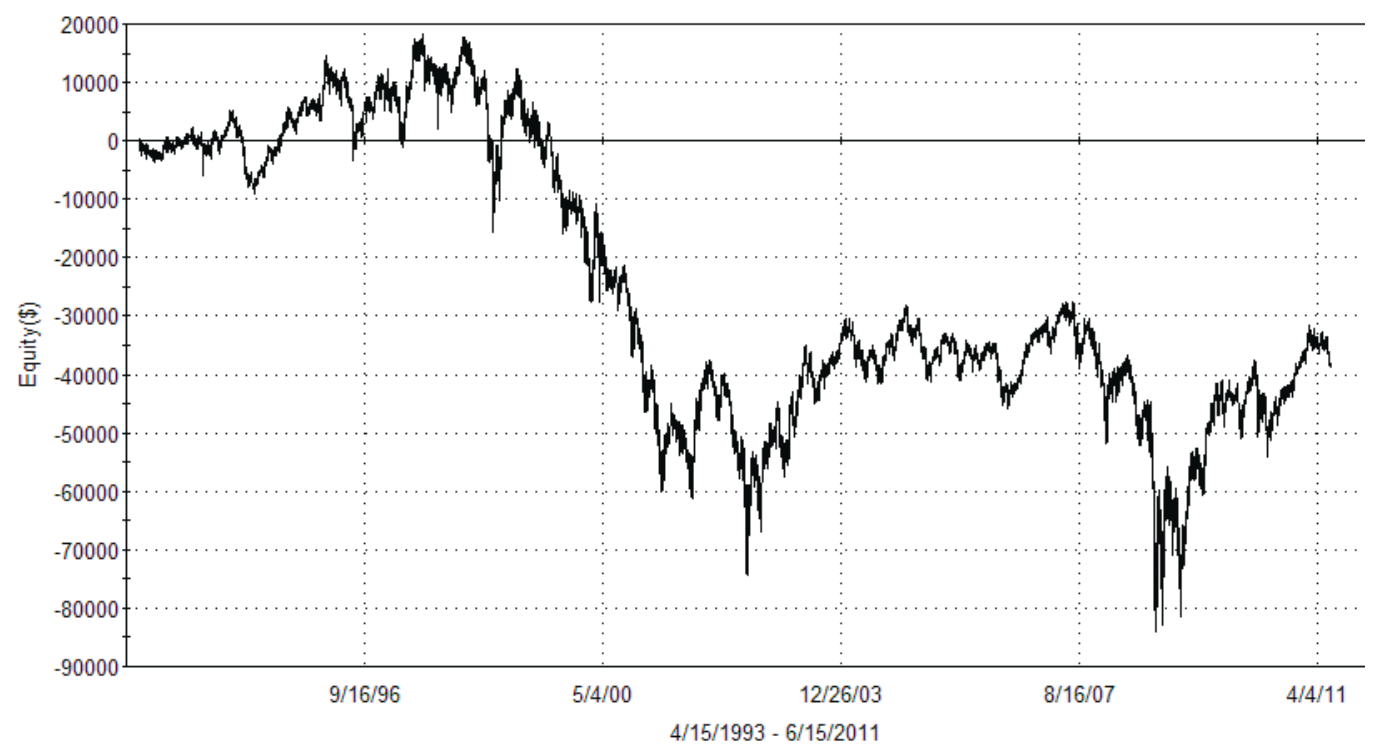

Figure 4. SPDR S\&P 500 ETF, from 2/2/1993 to 15/06/2011

Note. The equity curve of Daytime Returns (today's close - today's open) of $\$ 100,000$ invested/trade is displayed. Transactions don't include commission or slippage costs.

\section{Analysis: The Overnight Return Temporal Market Anomaly}

In this Section, the innovative term The Overnight Return Temporal Market Anomaly is defined, analyzed and documented. So, The Overnight Return Temporal Market Anomaly is defined as a two-dimension (2D) array of temporal trading functionalities (TTF), following the definition of the ORA rule (Section 1), applied both to daytime and overnight trading; and obey and restricted by stock's (instruments) price action patterns like Gaps ("Windows" in technical analysis terminology) and Breakouts. These TTF temporal functionalities are, for this temporal market anomaly, short-term functionalities parameterized by popular very short price action time-frames ([1-minute], [2-minute]); and they could be documented by time-targets in trading securities and instruments (stocks, options, futures, Forex, bonds, warrants, 3x ETF/ETN, etc.) as follows: executive define the Overnight Return Temporal Market trading strategy (open/close long/short positions) on specific time-targets. An example of an open-position time-target could be the last 5 minutes time period before the "closing bell" (i.e. 03:55-04:00 pm EST; New York time), and an example of a close-position time-target could be the first 5 minutes time period after the "opening bell" (i.e. 09:30-09:35 am EST; New York time). The TTF temporal functionalities operate as, complementary to above time-targets, warning dynamics trading signals when they are related to particular candlestick and price action pattern-targets.

Following, Tables 1-4 present, for the 3x ETN/instrument UGAZ and the 1x ETF SPY, the related trade performance distributions based on the above definition of the overnight return specific time-targets. Also, for the overnight return trading strategies, the TTF functionalities operate as warning dynamics signals (w!D signals), awaiting the final confirmation signal (e.g. candlestick Break; Jesse Livermore's resistance pivotal-line Breakout; Jesse Livermore's support pivotal-line Breakdown) just before the triggering (i.e. Open/Close position) during the executive overnight return period (i.e. the first/last 5 minutes during the trading session).

\subsection{The Overnight versus Daytime Returns}

The relation Overnight Return vs. Daytime Return is defined by analyzing the differences in returns between the overnight period and the trading session (NYSE: 9:30 am-4:00 pm). For volatility-strategy and volatility-tactical purposes, a back-test procedure has been applied on both, a 3x ETN instrument (UGAZ) and a 1x ETF instrument (SPY). This procedure generated, for these two instruments, 3,820 and 4,624 trades respectively.

Individual trades contain more information and trading TTF functionality after hours (overnight) than during the daily session (intraday: 09:30 am - 04:00 pm EST). Hence, because the information asymmetry declines over the intraday trading hours, price changes are larger, reflect more private information and trading functionality, and they are less noisy before the open than after the bell-clock. 
Table 1 presents, in summary, the annual returns (\%) after the application of the backtest procedure to the $3 x$ instrument UGAZ, for the period: $1^{\text {st }}$ January $2010-30^{\text {th }}$ June 2016 (3,820 trades generated). I note that the UGAZ has an annual overnight return of $8.61 \%$, while the annual daytime return is $-4.90 \%$. Additionally, a quality analysis, based on the recorded standard deviation values, says that -surprisingly- an overnight return trading strategy is less risky than a daytime return strategy, because of the lower annual std. dev. $(\sigma)$ value recorded in overnight vs. daytime returns. This is why the statistical quality indicator Sharpe Ratio (which does not include in calculations the risk-free interest rate) for the overnight period is 0.93 , compared to the -0.30 of the daytime period.

Table 1. UGAZ 3x leveraged ETN: Annual returns (\%) from a backtesting procedure (3,820 trades)

\begin{tabular}{ccccc}
\hline & \multicolumn{4}{c}{ Trading Results (\%) } \\
\hline & Annual Return & Annual std. dev. & Sharpe Ratio & Total Return \\
\hline Overnight Return Strategy & $8.61 \%$ & $11.92 \%$ & 0.93 & $130.42 \%$ \\
Daytime Return Strategy & $-4.90 \%$ & $18.10 \%$ & -0.30 & $-67.31 \%$ \\
\hline
\end{tabular}

Table 2 presents, in summary, the annual returns (\%) after the application of the backtest procedure to the $1 \mathrm{x}$ instrument SPY, for the period: $2^{\text {nd }}$ February $1993-15^{\text {th }}$ June 2011 (4,624 trades generated) (Skyba, 2012).

Table 2. SPDR S\&P 500 1x leveraged ETF: Annual returns (\%) from a backtesting procedure (4,624 trades)

\begin{tabular}{ccccc}
\hline & \multicolumn{4}{c}{ Trading Results (\%) } \\
\hline & Annual Return & Annual std. dev. & Sharpe Ratio & Total Return \\
\hline Overnight Return Strategy & $9.23 \%$ & $10.46 \%$ & 0.89 & $171.29 \%$ \\
Daytime Return Strategy & $-4.33 \%$ & $17.05 \%$ & -0.25 & $-39.36 \%$ \\
\hline
\end{tabular}

A comparative return analysis of $3 x$ leveraged UGAZ and 1x leveraged SPY, if it is temporaly (daily, annualy, total period) parameterized, indicates that the $1 \mathrm{x}$ instrument has had better performance annualy and totally, whilst the 3x instrument achives better results in daily (if you are on the right side). This is because of the well-known in Wall Street $3 x$ leveraged paradox, i.e. both (long) leveraged and (short) inverse-leveraged 3x instruments, of the same underline asset or index, in the long term decline in price.

\subsection{Trade Performance Analysis}

Tables 3 and 4 present the trade performance analysis results after applying the backtesting procedure on both instruments. For statistical backtesting purposes, a capital of $\$ 100,000$ has been invested per trade. Commission cost of $\$ 0.01$ per traded share results on significant (net) profit decrease as shown in Tables 3 and 4.

Please note that in case of a commission cost of $\$ 0.02$ per share, the total net profit of both overnight and daytime return strategies would be less than zero. Even worst, if we add any slippage cost in overnight return strategy. But, thanks to internet-based low-cost brokerage nowadays available, commission cost is very low (\$0.005) and slippage cost is not applicable.

Table 3. UGAZ 3x leveraged ETN: Trade performance analysis from backtesting data $(\$ 100,000$ invested per trade; Total period: 1/1/2010 - 30/6/2016)

\begin{tabular}{cccccc}
\hline & $\begin{array}{c}\text { Total number } \\
\text { of trades }\end{array}$ & $\begin{array}{c}\text { Winner } \\
\text { trades }\end{array}$ & $\begin{array}{c}\text { Loser } \\
\text { trades }\end{array}$ & $\begin{array}{c}\text { Profit without commission } \\
\text { cost }\end{array}$ & $\begin{array}{c}\text { Net Profit with commission } \\
\text { cost } \$ 0.01 \text { per share }\end{array}$ \\
\hline Overnight Return Strategy & 3,820 & 2,112 & 1,670 & $\$ 130,420$ & $\$ 49,666$ \\
Daytime Return Strategy & 3,820 & 1,850 & 1,922 & $\$-67,310$ & $\$-148,064$ \\
\hline
\end{tabular}

Table 4. SPDR S\&P 500 1x leveraged ETF: Trade performance analysis from backtesting data $(\$ 100,000$ invested per trade; Total period: 2/2/1993 - 15/6/2011)

\begin{tabular}{|c|c|c|c|c|c|}
\hline & $\begin{array}{c}\text { Total number } \\
\text { of trades }\end{array}$ & Winner trades & $\begin{array}{l}\text { Loser } \\
\text { trades }\end{array}$ & $\begin{array}{c}\text { Profit without } \\
\text { commission cost }\end{array}$ & $\begin{array}{c}\text { Net Profit with commission } \\
\text { cost } \$ 0.01 \text { per share }\end{array}$ \\
\hline Overnight Return Strategy & 4,624 & 2,480 & 2,112 & $\$ 171,289$ & $\$ 73,539$ \\
\hline Daytime Return Strategy & 4,624 & 2,234 & 2,371 & $\$-39,360$ & $\$-137,110$ \\
\hline
\end{tabular}




\section{Conclusions \& Discussion}

Price action is more efficient and therefore more information and trading functionality is revealed per hour during the intraday session than after hours (overnight). However, the after-hours overnight low trading volume generates significant trading opportunities (albeit inefficient) and offer great price action analysis and a new market anomaly discovery.

The main goal of this paper was to introduce an innovative market anomaly relating to time during the overnight trading session and therefore characterized as a temporal market anomaly. Anomalies in the markets appear on occasion and challenge the efficient market hypothesis. Many within the financial community believe that the markets follow the efficient market hypothesis. This theory asserts that the current price of a security reflects all public and private information about that security. Changes in price are due to current news or events, which are impossible to predict. Thus, the price action follows the path of a random walk, the premise of which states that current price is not dependent on past price and it is normally distributed over time (Vayanos \& Woolley, 2013; Lou et al., 2016; Livermore 1940/2001).

Individual trades contain more information and trading TTF functionality after hours (overnight) than during the daily session (intraday: 09:30 am - 04:00 pm EST). Hence, because the information asymmetry declines over the intraday trading hours, price changes are larger, reflect more private information and trading functionality, and they are less noisy before the open than after the bell-clock.

Over the years, many studies have presented data about what academics call "market anomalies" These anomalies appear from time to time and challenge the efficient market hypothesis. There are three common classifications: Fundamental, Technical, and Calendar-based Anomalies. There is another class of anomalies that simply could be referred to as "temporal" because of the timing functionality involved. In this article we discussed one of these "temporal" anomalies, called the overnight return temporal market anomaly.

The proposed volatility-strategy and volatility-tactical can be used in concert with ETFs, ETNs, swaps, futures, and/or options to implement risk management strategies and it is dedicated to providing individual traders and institutional investors with sophisticated solutions for portfolio and trading risk management. The proposal's success results from delivering innovative, efficient, and intelligent functionality for a wide range of intraday traders and institutional investors.

Paper contributes to corporate finance literature by: (a) the introduction of the new market inefficiency category "temporal market anomalies"; (b) the introduction, defining, analyzing and documentation of the innovative term "the overnight return temporal market anomaly" as a temporal market anomaly; and (c) the comparative analysis of the executive application (back-testing case study) of these new terms in two instruments, one $3 x$ leveraged ETN and another 1x leveraged ETF.

The trade performance analysis applied on these instruments, demonstrated that in a nowadays internet-based trading with very low commission cost and none slippage cost; a well designed overnight return strategy could gain benefit at the expense of short-term and intraday non-commercial speculators.

\section{Acknowledgments}

The financial support (covering mainly the CoT/CFTC and the Barron's \& WSJ.com market data expenses) from the EU/LLP Programme "EPOCHE 2013" (with Project No. 2012-1-GR-ERA10-10609) is gratefully acknowledged.

\section{Conflict of Interests}

The author has not declared any conflict of interests.

\section{References}

Alti, A., \& Sulaeman, J. (2012). When do high stock returns Trigger Equity Issues? Journal of Financial Economics, 103, 61-87. http://dx.doi.org/10.1016/j.jfineco.2011.08.007

Ang, A., Hodrick, R. J., Xing, Y., \& Zhang, X. (2006). The Cross-Section of Volatility and Expected Returns. Journal of Finance, 61, 259-299. Retrieved from http://web.ics.purdue.edu/ zhang654/jf2006.pdf

Baker, M., \& Wurgler, J. (2002). Market Timing and Capital Structure. The Journal of Finance, 57, 1-32. http://dx.doi.org/10.1111/1540-6261.00414

Baker, M., Stein, J. C., \& Wurgler, J. (2003). When does the Market Matter? Stock Prices and the Investment of Equity-dependent Firms. The Quarterly Journal of Economics, 118, 969-1005. http://dx.doi.org/10.1162/00335530360698478 
Bali, T. G., \& Cakici, N. (2008). Idiosyncratic Volatility and the Cross Section of Expected Stock Returns. Journal of Financial and Quantitative Analysis 43, 29-58. Retrieved from http://citeseerx.ist.psu.edu/viewdoc/download?doi=10.1.1.468.6852\&rep=rep1\&type=pdf

Barclay, M. J., \& Hendershott, T. (2003). Price Discovery and Trading After Hours. The Review of Financial Studies, 16(4), 1041-1073. http://dx.doi.org/10.1093/rfs/hhg030

Barron's Financial Investment News and Market Data. (2016). Retrieved from http://www.barrons.com/data; and http://www.wsj.com; and http://www.wsj.com/europe

Basdekidou, V. A. (2015). Functionality, Returns and Efficiency before and after the Debt Crisis: An Empirical Analysis of the Greek Stock Market (Unpublished doctoral dissertation). Bulgarian Academy of Sciences -Economic Research Institute, Bulgaria.

Basdekidou, V. A. (2016a). IPO Trading with Short-term and Intraday Temporal Functionalities. Business and Economics Journal, 7(4). http://dx.doi.org/10.4172/2151-6219.1000257

Basdekidou, V. A. (2016b). Personalized Temporal Trading Functionalities Engaged in Calendar Market Anomalies: Empirical Evidences from the 2007 and 2009 Financial Crises. Journal of Business \& Financial Affairs, 5(4). http://dx.doi.org/10.4172/2167-0234.1000225

Basdekidou, V. A. (2017). Seasoned Equity Offerings as Technical Market Anomalies: Long-Term Temporal Trading Functionalities. International Journal of Economics and Finance, 9(1), 96-105. http://dx.doi.org/10.5539/ijef.v9n1p96

Basdekidou, V. A., \& Styliadou, A. A. (2017). Technical Market Anomalies: Leveraged ETF Trading with Daily and Intraday Temporal Functionalities. Business and Economics Journal, 8(1). http://dx.doi.org/10.4172/2151-6219.1000275

Campbell, J. Y., Giglio, S., Polk, C., \& Turley, R. (2014). An Intertemporal CAPM with Stochastic Volatility. London School of Economics and Political Siences working paper, LSE London, UK. Retrieved from https://pdfs.semanticscholar.org/0044/748cabfc0ee3f7fdeea1992ce8efd7aaaa5f.pdf

Cesari, A. D., Espenlaub, S., Khurshed, A., \& Simkovic, M. (2012). The Effects of Ownership and Stock Liquidity on the Timing of Repurchase Transactions. Journal of Corporate Finance, 18, 1023-1050. http://dx.doi.org/10.1016/j.jcorpfin.2012.06.004

Chemmanur, T. J., He, S., \& Hu, G. (2009). The role of Iinstitutional Investors in Seasoned Equity Offerings. Journal of Financial Economics, 94, 384-411. http://dx.doi.org/10.1016/j.jfineco.2008.12.011

Chen, X., Harford, J., \& Li, K. (2007). Monitoring: Which institutions matter? Journal of Financial Economics, 86, 279-305. http://dx.doi.org/10.1016/j.jfineco.2006.09.005

Choie, K. S. (2016). Factors of IPO Underpricing. International Journal of Economics and Finance, 8(2), 107-114. http://dx.doi.org/10.5539/ijef.v8n2p107

Demiralp, I., D’Mello, R., Schlingemann, F. P., \& Subram Aniam, V. (2011). Are there Monitoring Benefits to Institutional Ownership? Evidence from Seasoned Equity Offerings. Journal of Corporate Finance, 17, 1340-1359. http://dx.doi.org/10.1016/j.jcorpfin.2011.07.002

Edelen, R. M., Ince, O., \& Kadlec, G. B. (2015). Institutional Investors and Stock Return Anomalies. E- Journal SSRN. http://dx.doi.org/10.2139/ssrn.2359744

Gaspar, J. M., Massa, M., \& Matos, P. (2005). Shareholder Investment Horizons and the Market for Corporate Control. Journal of Financial Economics, 76, 135-165. http://dx.doi.org/10.1016/j.jfineco.2004.10.002

Gibson, S., Safieddine, A., \& Sonti, R. (2004). Smart investments by smart money: Evidence from seasoned $\begin{array}{lllll}\text { equity offerings. Journal of Financial Economics, } & \text { 72, }\end{array}$ http://dx.doi.org/10.1016/j.jfineco.2003.05.001

Hao, G. Q. (2014). Institutional shareholder investment horizons and seasoned equity offerings. Financial Management, 43, 87-111. http://dx.doi.org/10.1111/fima.12038

Hartzell, J. C., \& Starks, L. T. (2003). Institutional Investors and Executive Compensation. Journal of Finance, 58, 2351-2374. http://dx.doi.org/10.1046/j.1540-6261.2003.00608.x

Hovakimian, A., \& Hu, H. (2016). Institutional Shareholders and SEO Market Timing. Journal of Corporate Finance, 36, 1-14. http://dx.doi.org/10.1016/j.jcorpfin.2015.09.009 
Livermore, J. (2001). How to Trade in Stocks. (R. Smitten, Translation). New York, NY: McGraw-Hill, 179 pages, ISBN: 0-07-146979-6. (Original work published 1940)

Lou, D., Polk, C., \& Skouras, S. (2016). A Tug of War: Overnight versus Intraday Expected Returns. London School of Economics and Political Sciences working paper, LSE London, UK. Retrieved from http://personal.lse.ac.uk/loud/overnightmom.pdf

Markoulis, S. N., \& Neofytou, N. (2016). An Empirical Analysis of the Relationship between Oil Prices and Stock Markets. International Journal of Economics and Finance, 8(12), 120-131. http://dx.doi.org/10.5539/ijef.v8n12p120

Nguyen, X. M., \& Tran, Q. T. (2016). Dividend Smoothing and Signaling Under the Impact of the Global Financial Crisis: A Comparison of US and Southeast Asian Markets. International Journal of Economics and Finance, 8(11), 118-123. http://dx.doi.org/10.5539/ijef.v8n11p118

Nickerson, D. (2016). Asset Price Volatility, Credit Rationing and Rational Lending Discimination. International Journal of Economics and Finance, 8(10), 140-158. http://dx.doi.org/10.5539/ijef.v8n10p140

Ogden, J. P., \& Wu, S. (2013). Reassessing the Effect of Growth Options on Leverage. Journal of Corporate Finance, 23, 182-195. http://dx.doi.org/10.1016/j.jcorpfin.2013.08.008

Skyba, E. (2012). The Overnight Return Study. Stocks \& Commodities, 30(2), 34-38. Retrieved from http://technical.traders.com/archive/articlefinal.asp?file=IV30\C02\241SKYB.pdf

Styliadis, A. D. (2007). E-learning Documentation of Historical Living Systems with 3-d Modeling Functionality. Informatica, 18(3), 419-446. Retrieved from http://www.mii.vu.lt/informatica/pdf/INFO686.pdf

Styliadis, A. D., \& Vassilakopoulos, M. G. (2005). A Spatio-Temporal Geometry-based Model for Digital Documentation of Historical Living Systems. Information \& Management, 42(2), 349-359. http://dx.doi.org/10.1016/j.im.2004.01.006

Vayanos, D., \& Woolley, P. (2013). An Institutional Theory of Momentum and Reversal. Review of Financial Studies, forthcoming. London School of Economics and Political Sciences working paper. LSE London, UK. Retrieved from http://personal.lse.ac.uk/vayanos/Papers/ITMR_RFS13.pdf

VelocityShares. (2017). Retrieved from http://www.velocitysharesetns.com/

Yan, X., \& Zhang, Z. (2009). Institutional Investors and Equity Returns: Are Short-term Institutions Better Informed? The Review of Financial Studies, 22, 893-924. http://dx.doi.org/10.1093/revfin/hhl046

\section{Notes}

Note 1. ETF: Exchange-Traded Funds; ETN: Exchange-Traded Notes.

Note 2. VelocityShares ${ }^{\circledR}$ is a leader in designing exchange-traded products, instruments (ETF, ETN) and sophisticated volatility strategies for institutional investors. The team is focused on developing liquid instruments that enable institutional investors to manage their risk, generate additional yield and express short-term market views. The team has significant experience across asset classes on both the buy- and sell-sides of the financial markets. Employing that combined knowledge and insight enables the development and delivery of innovative products.

\section{Copyrights}

Copyright for this article is retained by the author, with first publication rights granted to the journal.

This is an open-access article distributed under the terms and conditions of the Creative Commons Attribution license (http://creativecommons.org/licenses/by/4.0/). 